\title{
Congenital Anomalies in Low- and Middle-Income Countries: The Unborn Child of Global Surgery
}

\author{
Nicole A. Sitkin • Doruk Ozgediz • Peter Donkor • \\ Diana L. Farmer
}

Published online: 19 August 2014

(C) Société Internationale de Chirurgie 2014

\begin{abstract}
Surgically correctable congenital anomalies cause a substantial burden of global morbidity and mortality. These anomalies disproportionately affect children in low- and middle-income countries (LMICs) due to sociocultural, economic, and structural factors that limit the accessibility and quality of pediatric surgery. While data from LMICs are sparse, available evidence suggests that the true human and financial cost of congenital anomalies is grossly underestimated and that pediatric surgery is a cost-effective intervention with the potential to avert significant premature mortality and lifelong disability.
\end{abstract}

\section{Introduction}

If surgery is the "neglected stepchild of global health" [1], pediatric surgery is the child not yet born. Despite powerful

N. A. Sitkin $(\varangle) \cdot$ D. L. Farmer

Department of Surgery, University of California, Davis,

Sacramento, CA, USA

e-mail: nasitkin@ucdavis.edu

D. L. Farmer

e-mail: diana.farmer@ucdmc.ucdavis.edu

D. Ozgediz

Department of Surgery, Yale University School of Medicine,

New Haven, CT, USA

P. Donkor

Department of Surgery, School of Medical Sciences, College of Health Sciences, Kwame Nkrumah University of Science and

Technology, Kumasi, Ghana

P. Donkor

Department of Maxillofacial Sciences, Dental School, College of Health Sciences, Kwame Nkrumah University of Science and

Technology, Kumasi, Ghana

D. L. Farmer

Department of Surgery, University of California, Davis School of Medicine, University of California, Davis Health System, 2221 Stockton Blvd, Suite 3112, Sacramento, CA 95817, USA strides forward in the treatment of congenital anomalies, or birth defects, the benefits of these diagnostic and therapeutic advances have been largely confined to high-income countries (HICs), where many once fatal conditions can now be treated, with mortality rates under $10 \%$. In contrast, mortality rates from hospital-based data in low- and middle-income countries (LMICs) for common anomalies often rise to $20-85 \%$ [2-17]. Patients with immediately life-threatening conditions may die in transit or at home, and never be entered into such hospital-based measures $[18,19]$; the resultant hidden mortality represents an oftunderestimated addition to the burden of disease. This review article will summarize the growing body of knowledge on surgical congenital anomalies in LMICs and will highlight key research recommendations. An expanded version of this review will be published as a book chapter in Disease Control Priorities 3, Volume 3: Essential Surgery.

Congenital anomalies and the global burden of disease

Congenital anomalies account for a staggering 25.3-38.8 million disability-adjusted life-years (DALYs) worldwide $[20,21]$. DALYs are a well established metric for measuring the burden of disease in terms of both mortality and morbidity; 1 DALY is 1 healthy year of life lost due to 
disability or premature death. The World Health Organization's (WHO) recent global burden of disease (GBD) study reports that anomalies rank 17th in causes of disease burden [20]. While impressive, these figures are likely underestimates due to the limited number of anomalies included and the difficulties in evaluating incidence, morbidity, and mortality. Only six anomalies were assigned disability weights in the previous 2004 estimates, and new disability weights were not estimated for congenital anomalies in 2012 [21, 22]. Some researchers have tried to fill the gap with evidence-based estimates of selected disability-weights [23]. Of the conditions measured in the GBD study, cardiac defects represent the greatest overall burden, and, with neural tube defects and cleft lip and palate, cause 21 million DALYs. Of these, $57 \%$, or 12 million are estimated to be surgically avertable if outcomes in HICs could be achieved in LMICs [24]. The GBD study also reports 361 DALYs per 1,000 population globally [20]. Strikingly, congenital anomalies may be responsible for up to 120 DALYs per 1,000 children [25].

In general, current estimates of the surgical burden of disease are considered a "best educated guess," given the "near total lack of pertinent data" [26]. Even less is known about pediatric surgical disease [27]. Extant research paints a brutal picture of the potential scope and human cost of pediatric surgical disease.

\section{Incidence, prevalence and treatment of congenital anomalies in LMICs}

A total of $94 \%$ of anomalies occur in LMICs [28]. Higher fertility rates translate to higher birth rates and net prevalence of anomalies. In addition, the frequency of pregnancy termination following prenatal diagnosis of a congenital anomaly is lower in many LMICs than in HICs. In part, this difference stems from the fact that elective pregnancy termination following prenatal diagnosis may be less available in certain LMICs than in HICs. Despite a global trend towards liberalization of termination laws, legal and procedural pushback limit access to pregnancy termination services in many countries around the world [29].

Incidence (the frequency with which a disease occurs in a given population) is also higher in LMICs. This jump has been attributed to an interaction of multiple contextual factors, including increased nutritional deficiency, prevalence of intrauterine infection, exposure to teratogens, and self-medication with unsupervised drugs or traditional remedies [30, 31]. Although decreasing the birth rate may reduce the net prevalence of congenital anomalies, most anomalies cannot otherwise be prevented and must be treated surgically.
Many LMICs lack rigorous congenital anomaly surveillance programs, making accurate calculations of incidence and prevalence difficult [31]. Current calculations, which range from 4 to 12 cases per 1,000 births, are likely underestimates due to stigma and exclusion [32-34]. In addition, the emergent nature of some anomalies can skew incidence and prevalence data. Children with non-immediately life-threatening anomalies are more likely to survive until treatment than children with immediately lifethreatening conditions. Hospital-based data therefore inherently biases the perception of relative incidence and prevalence such that immediately life-threatening conditions may appear to have a lower incidence than nonimmediately life-threatening anomalies [35]. Populationbased surveys-which directly collect data from non-centralized sites-represent one approach to addressing this challenge [25].

The burden of disease associated with congenital anomalies in LMICs is most often calculated as the mortality rate over a given period of time. These data can be challenging to analyze in LMICs. In Benin, for example, only $0.8 \%$ of nearly 1,100 neonatal deaths were investigated with an autopsy. In all examined cases, autopsy provided additional information on the cause of death [36]. Additionally, non-fatal anomalies can result in extensive, ongoing morbidity. The burden of disease is grossly underestimated if measures of this impairment are not included. Indeed, anomalies resulting in visible deformity (such as clubfoot and cleft lip) or non-visible anomalies that cause chronic disability may also cause stigmatization, which can trigger abandonment or infanticide. An 'incurable' anomaly may endanger the whole family's wellbeing, as key resources must be allocated to care for the afflicted child. Families may fracture, with one or both parents leaving the child with other family members. While extant calculations of the burden of disease neglect to measure these harms, these calculations do highlight marked disparities in survival rates between HICs and LMICs.

Heightened mortality rates stem from a complex web of social, economic, and geographic factors. In LMICs, many births occur at home, either with no attendants or with traditional birth attendants; pejorative cultural beliefs or ignorance about possible cures for defects may prevent families from seeking treatment. If families do seek care, they must often travel great distances to reach medical facilities. Hypothermia is common following unsupervised transport over long distances, with severe repercussions on outcomes [13, 14, 37]. Misdiagnosis as better known infectious diseases is common, as are added delays in diagnosis for non-visible anomalies. These challenges are exacerbated by the paucity of specialized providers in LMICs. One pediatric general surgeon may serve millions 
of children [38], and physicians performing pediatric surgery may have little or no pediatric surgery training [39, 40]. While North America has an estimated one pediatric cardiac surgeon per 3 million people, sub-Saharan Africa has one per 38 million people [41]; $75 \%$ of the world's population is estimated to have no access to cardiac surgery [42]. Similarly, one-third of the world's population is covered by one-twentieth of its neurosurgeons [43]. Delays in referring patients from local health centers to medical centers with specialized surgical capacity, and the financial burden of treatment on families, also limit the accessibility of treatment for congenital anomalies.

The power of pediatric surgery to reduce the global burden of disease

Only a small body of literature evaluates the potential of surgery to reduce the burden of disease associated with congenital anomalies in terms of DALYs averted or cost effectiveness. Yet these foundational studies have provided compelling evidence that pediatric surgery represents a cost-effective intervention with the potential to avert over two-thirds of the DALYs associated with birth defects [24, 25, 34, 44-46]. Favorable outcomes have been reported in HICs for anomalies such as anorectal malformations and congenital diaphragmatic hernia [47]. In LMICs, the human capital approach to cleft lip and palate repair has provided very favorable cost-effectiveness analysis (CEA) estimates. An extension of this methodology to treatment for hydrocephalus in Uganda yielded a cost of \$US59-126 per DALY averted [48]. Surgical repair of congenital inguinal hernias in Uganda was estimated to have an incremental cost-effectiveness ratio (ICER) of \$US12/ DALY averted [49]. Another recent report from Cambodia estimated a CEA of \$US99/DALY averted over 3 months for reconstructive surgery for an array of anomalies [50].

Critically, treating congenital anomalies may translate into a significantly greater reduction in the economic burden of disease than that cited above. Since children represent the future economic engine powering LMICs, the value of investing in pediatric surgery also encompasses the future socioeconomic well-being of LMICs. In order to take advantage of the inherent upside to treating congenital disease at its inception, research must address the knowledge gaps that currently impede the development of effective care systems.

\section{Recommended research priorities for pediatric surgery in LMICs}

Based on the available literature, research priorities to improve pediatric surgery capacity and reduce the burden of disease attributable to congenital anomalies include the following:

1. Epidemiology, prevalence, and incidence of disease. Epidemiology may vary locally, but additional data are needed [51]. Registries for selected anomalies may assist in improving surveillance (e.g. by participation in the International Clearinghouse for Birth Defects Surveillance and Research). Evaluation of hidden mortality and morbidity will better approximate the true burden of disease.

2. Pediatric surgical capacity at all levels of the health system. Guidelines for minimum human resources and infrastructure for countries at different levels of development. While the WHO Situational Analysis Tool (which evaluates gaps in the availability of emergency and essential surgical care) only includes two items pertaining to pediatric surgical care, an alternative capacity tool has recently been proposed [52]. This tool could be refined and further evaluated as it is piloted in different countries. While surgical outreach programs tackle the backlog of non-emergent conditions, emergent conditions require development of the whole health system. More work is needed to define and develop the mechanisms to strengthen systems for pediatric surgery.

3. Optimized quantitative metrics of disease burden. While well accepted, DALYs are difficult to apply practically. Surgical backlogs can be calculated for congenital anomalies and can be a useful advocacy tool to estimate the resources needed to treat common, non-fatal anomalies. In MICs and HICs, many prevalent congenital anomalies are treated in the first year of life; in LICs, they are never treated or are treated years later, after children have suffered unnecessary complications. Improved measurements of the burden imposed by delayed access to care have not yet been developed. However, as DALYs are currently the standard metric, calculating new or better disabilityweights for a broad range of congenital anomalies is also a viable means by which to improve meaningful evaluation of the contribution of congenital anomalies to the global burden of disease.

4. Models for the integration of pediatric surgical services within existing child health initiatives. Large-scale child health initiatives (such as the WHO Integrated Management of Childhood Illness and Neonatal Resuscitation) have not historically included surgical care. Similarly, congenital anomalies have not been addressed through the agenda of the noncommunicable disease movement, despite the fact that they are at times considered non-communicable disease (as in the WHO's recent GBD study). Many 
providers of children's surgical services share the concern that the surgical needs of children, if not explicitly addressed, are often neglected. Additionally, greater planning is needed between networks of specialty organizations and providers treating a broad range of congenital anomalies to collaborate where possible.

5. Cost-effectiveness data. To the author's knowledge, only two attempts to estimate cost effectiveness for pediatric surgical wards has been made $[34,50]$. Lowcost technical and technological innovations (such as telemedicine) hold great promise to improve perioperative care and training [53]. CEA of training programs could also aid in advocacy for greater resources for training.

6. Aligning marketing and advocacy. Greater emphasis has been directed toward selected visible, treatable anomalies (e.g. cleft lip and palate) than to a range of anomalies for which it has been more difficult to engage donor programs. Innovative strategies to improve the multidimensional measurement of the burden of disease are needed to make these treatable anomalies more salient for the public health community.

\section{Conclusion}

Great disparities exist in the accessibility and quality of pediatric surgical services between HICs and LMICs. This gap can only be bridged by jointly building pediatric surgical capacity in LMICs and by conducting rigorous research to better guide health system development and allocation of inherently limited resources. Local expertise and buy-in should be integrated whenever possible in order to create sustainable systems that increase long-term capacity and take advantage of the substantial potential intellectual, creative, and personnel resources of LMICs. It is an economic and moral imperative that global partners invest in pediatric surgery as a vital component of reducing the burden of disease and improving the public health and economic fortunes of LMICs. Healthy children remain the only future for society.

Acknowledgments The authors would like to thank the editorial and research staff of the Disease Control Priorities 3 project for their support in the development of the upcoming chapter that serves as the basis for this review article.

\section{References}

1. Farmer P, Kim J (2008) Surgery and global health: a view from beyond the OR. World J Surg 32:533-536. doi:10.1007/s00268008-9525-9
2. Peyvasteh M, Askarpour S, Javaherizadeh H, Fatahian T (2011) Evaluation of epidemiologic indices of neonate's diseases in the Pediatric Surgery Ward of the Ahvaz Jundishapur University hospitals during the period 1993-1996 and 2002-2005. Ann Pediatr Surg 7:7-9

3. Adejuyigbe O, Abubakar AM, Sowande OA, Olayinka OS, Uba AF (2004) Experience with anorectal malformations in Ile-Ife, Nigeria. Pediatr Surg Int 20:855-858

4. Tefera E, Teka T, Derbew M (2007) Neonatal gastrointestinal surgical emergencies: a 5-year review in a teaching hospital Addis Ababa, Ethiopia. Ethiop Med J 45:251-256

5. Adeyemi D (1989) Neonatal intestinal obstruction in a developing tropical country: patterns, problems, and prognosis. J Trop Pediatr 35:66-70

6. Ekenze SO, Agugua-Obianyo NEN, Amah CC (2007) Colostomy for large bowel anomalies in children: a case controlled study. Int J Surg 5(4):273-277

7. Chirdan LB, Uba AF (2006) Hirschsprung's disease presenting in the neonatal period in Jos, Nigeria. Nigerian J Surg Res $8(1-2): 62-64$

8. Shah G, Singh M, Pandey T, Kalakheti B, Bhandari G (2008) Incidence of congenital heart disease in tertiary care hospital. Kathmandu Univ Med J (KUMJ) 6(1):33-36

9. Wickramasinghe P, Lamabadusuriya SP, Narenthiran S (2001) Prospective study of congenital heart disease in children. Ceylon Med J 46:96-98

10. Islam MADMS, Aziz FPMA (2011) Esophageal atresia: outcome in 21 cases. Bangladesh Armed Forces Med J 44(6):47

11. Manson J, Ameh E, Canvassar N, Chen T, den Hoeve AV, Lever F et al (2012) Gastroschisis: a multi-centre comparison of management and outcome. Afr J Paediatr Surg 9:17-21

12. Askarpour S, Ostadian N, Javaherizadeh H, Chabi S (2012) Omphalocele, gastroschisis: epidemiology, survival, and mortality in Imam Khomeini Hospital, Ahvaz-Iran. Pol Przegl Chir 84(2):82-85

13. Sekabira J, Hadley GP (2009) Gastroschisis: a third world perspective. Pediatr Surg Int 25:327-329

14. Uba AF, Chirdan LB (2003) Omphalocoele and gastroschisis: management in a developing country. Nigerian J Surg Res 5:57-61

15. Toro MNH, Rave MEA, Gomez PMJ (2010) Management of abdominal wall defects (gastroschisis and omphalocele) at Hospital Universitario San Vicente de Paul, in Medellin, Colombia, 1998-2006. [Spanish]. Iatreia 23(3):220-226

16. Ozdogan T, Durakbasa C, Mutus M, Iscen M (2010) Congenital diaphragmatic hernia: a 4-year experience in a single centre. Afr J Paediatr Surg 7:105-106

17. Rohana J, Boo NY, Thambidorai CR (2008) Early outcome of congenital diaphragmatic hernia in a Malaysian tertiary centre. Singapore Med J 49:142-144

18. Ozgediz D, Jamison D, Cherian M, McQueen K (2008) The burden of surgical conditions and access to surgical care in low-and middle-income countries. Bull World Health Organ 86:646-647

19. Mo-suwan L, Isaranurug S, Chanvitan P, Techasena W, Sutra S, Supakunpinyo C et al (2009) Perinatal death pattern in the four districts of Thailand: findings from the Prospective Cohort Study of Thai Children (PCTC). J Med Assoc Thai 92:660-666

20. Murray CJL, Vos T, Lozano R, Naghavi M, Flaxman AD, Michaud C et al (2012) Disability-adjusted life years (DALYs) for 291 diseases and injuries in 21 regions, 1990-2010: a systematic analysis for the Global Burden of Disease Study 2010. Lancet 380:2197-2223

21. World Health Organization (2008) The global burden of disease: 2004 update. WHO Press, Geneva

22. Salomon JA, Vos T, Hogan DR, Gagnon M, Naghavi M, Mokdad A et al (2013) Common values in assessing health outcomes from 
disease and injury: disability weights measurement study for the Global Burden of Disease Study 2010. Lancet 380:2129-2143

23. Poenaru DPJ, Frankfurter C, Cameron B (2013) Establishing disability weights for congenital pediatric surgical disease. Lancet 381:S3115

24. Higashi H, Barendregt JJ, Vos T (2013) The burden of congenital anomalies amenable to surgeries in low-income and middleincome countries: a modelled analysis. Lancet 381:S62

25. Wu VK, Poenaru D, Poley MJ (2013) Burden of surgical congenital anomalies in Kenya: a population-based study. J Trop Pediatr 59:195-202

26. Measham AR, Alleyne G, Mills A, Musgrove P, Claeson M, Jamison DT et al (2006) Disease control priorities in developing countries. World Bank and Oxford University Press, Washington

27. Bickler SW, Rode H (2002) Surgical services for children in developing countries. Bull World Health Organ 80:829-835

28. World Health Organization (2012) Congenital anomalies: fact sheet $\mathrm{N}^{\circ} 370$. http://www.who.int/mediacentre/factsheets/fs370/ en/

29. Finer L, Fine JB (2013) Abortion law around the world: progress and pushback. Am J Pub Health 103:585-589

30. Christianson AL, Howson CP, Modell B (2006) Global report on birth defects: the hidden toll of dying and disabled children. March of Dimes Birth Defects Foundation, White Plains, NY

31. Penchaszadeh VB (2002) Preventing congenital anomalies in developing countries. Pub Health Genom 5:61-69

32. Bickler S, Ozgediz D, Gosselin R, Weiser T, Spiegel D, Hsia R et al (2010) Key concepts for estimating the burden of surgical conditions and the unmet need for surgical care. World J Surg 34:374-380. doi:10.1007/s00268-009-0261-6

33. Goksan SB, Bursali A, Bilgili F, Sivacioglu S, Ayanoglu S (2006) Ponseti technique for the correction of idiopathic clubfeet presenting up to 1 year of age. A preliminary study in children with untreated or complex deformities. Arch Orthop Trauma Surg 126:15-21

34. Wu V, Poenaru D (2013) Burden of surgically correctable disabilities among children in the Dadaab refugee camp. World J Surg 37:1536-1543. doi:10.1007/s00268-012-1899-z

35. Nandi B, Mungongo C, Lakhoo K (2008) A comparison of neonatal surgical admissions between two linked surgical departments in Africa and Europe. Pediatr Surg Int 24:939-942

36. Ugiagbe EE, Osifo OD (2012) Postmortem examinations on deceased neonates: a rarely utilized procedure in an African referral center. Pediatr Dev Pathol 15:1-4

37. Agarwala S, Bhatnagar V, Bajpai M, Gupta D, Mitra D (1996) Factors contributing to poor results of treatment of esophageal atresia in developing countries. Pediatr Surg Int 11:312-315

38. Chirdan LB, Ameh EA, Abantanga FA, Sidler D, Elhalaby EA (2010) Challenges of training and delivery of pediatric surgical services in Africa. J Pediatr Surg 45:610-618

39. Mhando S, Young B, Lakhoo K (2008) The scope of emergency paediatric surgery in Tanzania. Pediatr Surg Int 24:219-222
40. Ekenze SO, Ibeziako SN, Ezomike UO (2007) Trends in neonatal intestinal obstruction in a developing country, 1996-2005. World J Surg 31(12):2405-2409. doi:10.1007/s00268-007-9206-0

41. Bernier PL, Stefanexcu A, Samoukovic G, Tchervenkov CI (2010) The challenge of congenital heart disease worldwide: epidemiologic and demographic facts. Semin Thorac Cardiovasc Surg Pediatr Card Surg Annu 13(1):26-34

42. Hoffman JI (2013) The global burden of congenital heart disease. Cardiovasc J Africa 24:141

43. Warf BC (2013) Educate one to save a few. Educate a few to save many. World Neurosurg 79(2 Suppl):S15.e15-e18

44. Corlew DS (2010) Estimation of impact of surgical disease through economic modeling of cleft lip and palate care. World J Surg 34:391-396. doi:10.1007/s00268-009-0198-9

45. Ozgediz D, Poenaru D (2012) The burden of pediatric surgical conditions in low and middle income countries: a call to action. J Pediatr Surg 47(12):2305-2311

46. Poenaru D (2013) Getting the job done: analysis of the impact and effectiveness of the SmileTrain program in alleviating the global burden of cleft disease. World J Surg 37:1562-1570. doi:10.1007/s00268-012-1876-6

47. Poley MJ, Brouwer WB, Busschbach JJ, Hazebroek FW, Tibboel D, Rutten FF et al (2008) Cost-effectiveness of neonatal surgery: first greeted with scepticism, now increasingly accepted. Pediatr Surg Int 24:119-127

48. Warf BC, Alkire BC, Bhai S, Hughes C, Schiff SJ, Vincent JR et al (2011) Costs and benefits of neurosurgical intervention for infant hydrocephalus in sub-Saharan Africa. J Neurosurg Pediatr 8:509-521

49. Eason G LM, Birabwa-Male D, Reimer E, Pennington M, Blair G (2012) Costs and cost-effectiveness of pediatric inguinal hernia repair in Uganda. Abstract presented at European Paediatric Surgeons Association and British Association of Paediatric Surgeons Joint Congress, Rome

50. Rattray KW, Harrop TC, Aird J, Tam T, Beveridge M, Gollogly JG (2013) The cost effectiveness of reconstructive surgery in Cambodia. Asian Biomed 7(3):319-324

51. Bickler SW (2000) Non-communicable diseases: is their emergence in industrialized societies related to changes in neuroendocrine function? Med Hypotheses 54:825-828

52. Nacul LC, Stewart A, Alberg C, Chowdhury S, Darlison MW, Grollman C et al (2014) A Toolkit to assess health needs for congenital disorders in low- and middle-income countries: an instrument for public health action. J Public Health (Oxf) 36(2):243-250

53. Hadley GP, Mars M (2008) Postgraduate medical education in paediatric surgery: videoconferencing-a possible solution for Africa? Pediatr Surg Int 24:223-226 